scale and numerical rating scale) were recorded. NRD was expressed as $E M G_{\text {paramax }}$ : inspiratory $E M G_{\text {para }}$ signal normalised to a maximum signal measured during a sniff manoeuvre. The changes in $\mathrm{EMG}_{\text {para\%max }}\left(\right.$ ? $\left.\mathrm{EMG}_{\text {para\%max }}\right)$ and IC $(\Delta \mathrm{IC})$ between admission and discharge were analysed.

Results 31 patients were recruited; only 20 (65\%) were able to perform spirometry and IC manoeuvres. The baseline characteristics were $69 \pm 11$ years; male $55 \%$; body mass index $26.1 \pm 7.3 \mathrm{~kg} / \mathrm{m}^{2}$; \% predicted $\mathrm{FEV}_{1} 36.3 \pm 9.3$; and $41 \pm 24$ smoking pack years. The overall mean $\Delta \mathrm{EMG}_{\text {para\%max }}$ of the 20 patients fell by $4 \%$, with $16(80 \%)$ patients experiencing a fall in $\mathrm{EMG}_{\text {paramax }}$ during their admission. We observed an indirect relationship between $\Delta \mathrm{EMG}_{\text {para } \% \max }$ and $\Delta \mathrm{IC}(\mathrm{r}=-0.52, \mathrm{p}=0.02)$, and between $\Delta \mathrm{EMG}_{\mathrm{para} \% \max }$ and $\Delta \mathrm{FVC}$ $(\mathrm{r}=-0.585, \mathrm{p}=0.036)$. We found a correlation between $\Delta \mathrm{IC}$ and $\Delta \mathrm{FEV}_{1}(\mathrm{r}=0.658, \mathrm{p}=0.015)$. There were differences in $\Delta \mathrm{IC}$ between patients whose $\mathrm{EMG}_{\text {paramax }}$ decreased during their admission and those whose $\mathrm{EMG}_{\text {para\%max }}$ increased (mean difference $0.50 \mathrm{l}$; $\mathrm{p}=0.003$ ) (Abstract S116 figure 1). There were no significant correlations between dyspnoea scores and $\Delta \mathrm{IC}$ or $\Delta \mathrm{EMG}_{\text {para\%max }}$.

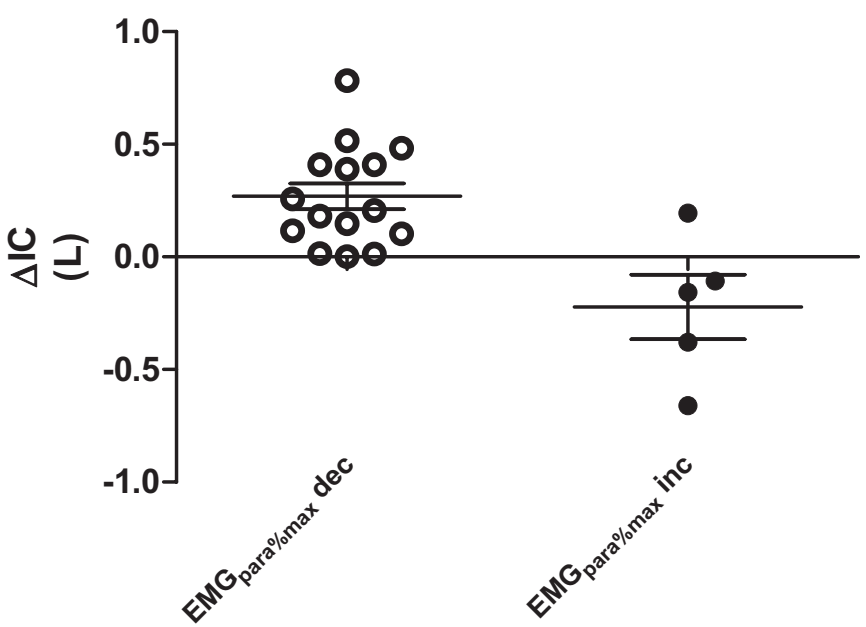

Abstract S116 Figure 1

Conclusion $\mathrm{DH}$ is a significant contributor to $\mathrm{NRD}$ in AECOPD. $\Delta \mathrm{EMG}_{\text {para\%max }}$ reflects changes in $\mathrm{DH}$ during hospital admission, but patient-reported dyspnoea does not indicate the degree of $\mathrm{DH}$, highlighting the limitations of dyspnoea scores. Changes in $\mathrm{DH}$ are correlated with changes in airflow obstruction. These data provide a physiological rationale for the utility of parasternal EMG as a noninvasive and non-volitional technique to track clinical change in AECOPD patients.

\section{S117 RESPIRATORY MUSCLE FATIGUE FOLLOWING EXERCISE IN PATIENTS WITH INTERSTITIAL LUNG DISEASE}

doi:10.1136/thoraxjnl-2011-201054b.117

D Elia, J L Kelly, D Martolini, E Renzoni, A K Boutou, A Chetta, M I Polkey, N S Hopkinson. NIHR Respiratory Biomedical Research Unit of Royal Brompton and Harefield NHS Trust and Imperial College, London, UK

Background Patients with interstitial lung disease (ILD) experience progressive breathlessness and exercise limitation. Although respiratory muscle fatigue has been investigated in healthy subjects and patients with COPD, it is unknown whether it occurs during exercise in ILD patients and, if so to what extent it is related to changes in dynamic lung volumes.

Methods Patients with ILD performed incremental, symptomlimited cycle ergometry with inspiratory capacity manoeuvres used to measure changes in end-expiratory lung volume (EELV). Twitch transdiaphragmatic pressure (TwPdi), in response to bilateral anterolateral magnetic phrenic nerve stimulation and twitch gastric pressure $\left(\mathrm{TwT}_{10} \mathrm{Pga}\right)$ in response to magnetic stimulation over the 10th thoracic vertebra were used to assess the development of fatigue.

Results Sixteen ILD patients (11 women) were studied. TwPdi did not differ significantly pre and post exercise (21.8 \pm 8 vs $20.2 \pm 8$ $\mathrm{cmH}_{2} \mathrm{O} ; \mathrm{p}=0.10$ ), while $\mathrm{TwT}_{10}$ Pga fell from $28.6 \pm 18$ to $25.2 \pm 14$ $\mathrm{cmH}_{2} \mathrm{O} \quad(\mathrm{p}=0.02) \quad$ (Abstract S117 figure 1). EELV fell from $2.18 \pm 0.651$ to $1.91 \pm 0.591$ following exercise $(p=0.04)$. The fall in $\mathrm{TwT10Pgas}$ correlated with peak $\mathrm{VO}_{2}(\mathrm{r}=-0.52, \mathrm{p}=0.041)$ increase in heart rate $(r=0.53 \mathrm{p}=0.032)$ and with the decrease of EELV during exercise $(r=0.57, p=0.021)$. Abdominal muscle fatiguers $(n=9,56 \%)$, defined as a $\geq 10 \%$ fall in TwT10Pga, had a fall in EELV of $22 \pm 22 \%$ compared to $0.7 \pm 8 \%$ in non-fatiguers $(p=0.016)$.
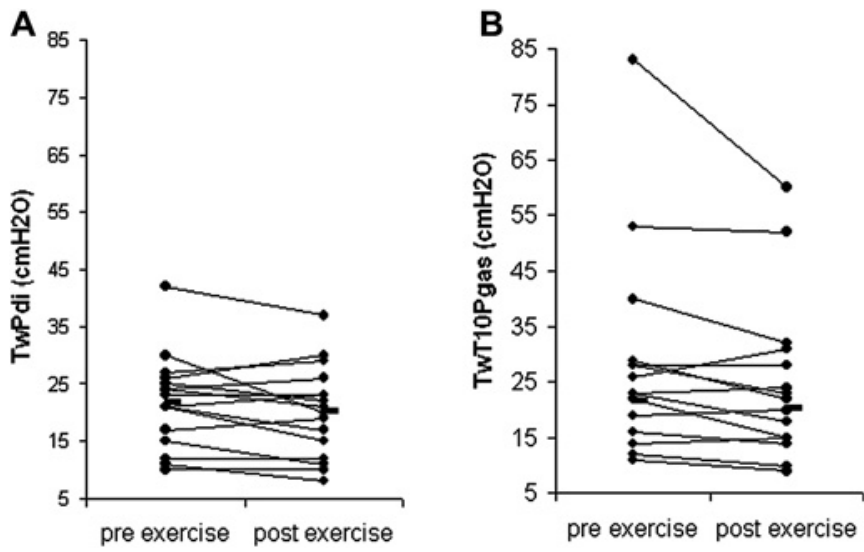

Abstract S117 Figure 1 Twitch transdiapragmatic $(A)$ and twitch gastric pressure (B) pressure before and after exercise.

Conclusion Abdominal muscle fatigue develops during exercise in ILD patients in association with increased expiratory muscle activity manifest by reduced EELV.

\section{S118 DIRECT VISUALISATION OF COLLATERAL VENTILATION IN COPD WITH HYPERPOLARISED GAS MRI}

doi:10.1136/thoraxjnl-2011-201054b.118

${ }^{1} \mathrm{H}$ Marshall, ${ }^{1} \mathrm{M} \mathrm{H}$ Deppe, ${ }^{1} \mathrm{~J}$ Parra-Robles, ${ }^{2} \mathrm{~S}$ Hillis, ${ }^{2} \mathrm{C}$ Billings, ${ }^{3} \mathrm{~S} \mathrm{R}$ Miller, ${ }^{3} \mathrm{~J} \mathrm{H}$ Watson, ${ }^{4} \mathrm{~J}$ Wolber, ${ }^{3} \mathrm{D}$ A Lipson, ${ }^{2} \mathrm{R}$ Lawson, ${ }^{1} \mathrm{~J} \mathrm{M}$ Wild. ${ }^{1}$ Academic Radiology, University of Sheffield, Sheffield, UK; ${ }^{2}$ Respiratory Medicine, Sheffield Teaching Hospitals NHS Trust, Sheffield, UK; ${ }^{3}$ GlaxoSmithKline, King of Prussia, Pennsylvania, USA; ${ }^{4}$ GE Healthcare, Amersham, UK

Introduction and Objectives Collateral ventilation is important in pathophysiology of Chronic Obstructive Pulmonary Disease (COPD), complicated pneumothorax, and bronchoscopic lung volume reduction surgery but limited observations of it in vivo have been attained. Current techniques capable of imaging collateral ventilation require monitoring over multiple breathing cycles and

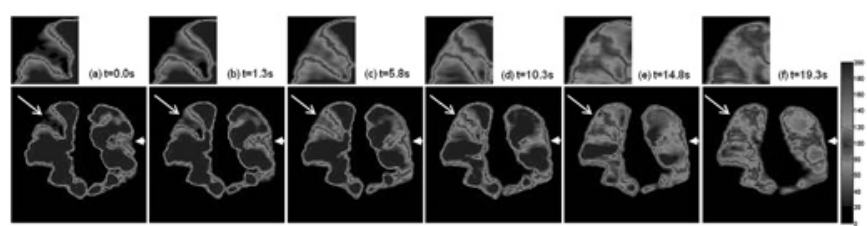

Abstract S118 Figure 1 Images tracking collateral ventilation in a COPD patient $(A-F)$, all displayed with the same colour-scale. 
use ionising radiation. Here we present the first single-breath demonstration of collateral ventilation, by using hyperpolarised gas MRI.

Methods Ten patients with moderate to severe COPD as defined by NICE guidelines were scanned using a 1.5T whole body MRI system. A mix of $200 \mathrm{ml}$ hyperpolarised ${ }^{3} \mathrm{He}$ and $800 \mathrm{ml} \mathrm{N}_{2}$ was inhaled, and ${ }^{3} \mathrm{He} \mathrm{MR}$ images were acquired. $3 \mathrm{D}$ images with full lung coverage were acquired at six time-points during a single breathhold.

Results Abstract S118 figure 1 shows example sequential images in one patient, with insets highlighting an area with late ventilation. Hyperpolarised ${ }^{3} \mathrm{He} \mathrm{MR}$ signal is non-renewable and diminishes over time. In normally ventilated regions of the lung this expected signal decay is observed. However, in the regions indicated with arrows the signal increases over time due to collateral ventilation, with a progressive influx of polarised gas from the edge of the defects towards the centre. The long time constants for ventilation of some areas are not compatible with their ventilation via their feeding bronchi. Instances of collateral ventilation were observed in eight of the ten patients scanned. These examples varied in defect size, number and fill-rate from the strongest case (Abstract S118 figure 1) to much more subtle effects.

Conclusions A method for direct visualisation of collateral ventilation within a single breath-hold has been demonstrated in COPD patients for the first time. The technique gives $3 \mathrm{D}$ full lung coverage, and is non-invasive and non-ionising. The ability to image collateral ventilation directly may help to understand pathophysiology in COPD and aid assessment for therapy.

\section{S119 UK HOT-HMV TRIAL: ACCEPTABILITY AND TOLERABILITY OF HIGH PRESSURE DOMICILIARY NON-INVASIVE VENTILATION (NIV) IN COPD}

doi:10.1136/thoraxjnl-2011-201054b.119

${ }^{1} \mathrm{P}$ B Murphy, ${ }^{1} \mathrm{~J}$ Moxham, ${ }^{2} \mathrm{M}$ I Polkey, ${ }^{3} \mathrm{~N}$ Hart. ${ }^{1}$ King's College London, London, UK; ${ }^{2}$ NIHR, Respiratory Biomedical Research Unit, Royal Brompton Hospital and Imperial College London, London, UK; ${ }^{3}$ Guy's \& St Thomas' NHS Foundation Trust and Kings College London NIHR Biomedical Research Centre, London, UK

Introduction Domiciliary NIV in COPD remains controversial with previous randomised controlled trials showing little clinical benefit. However, these trials have been criticised for using low pressure NIV and consequently nocturnal hypoventilation occurs. In contrast, there are genuine concerns that patients may not be able to tolerate the high pressure domiciliary NIV required to manage nocturnal hypoventilation effectively.

Method Patients admitted for acute hypercapnic respiratory failure due to an exacerbation of COPD with persistent hypercapnia $\left(\mathrm{PaCO}_{2}>7 \mathrm{kPa}\right) 2-4$ weeks following resolution of acute episode were offered participation into the trial. Patients were randomised to either home oxygen therapy (HOT) or home mechanical ventilation

Abstract S119 Table 1 Baseline charateristics

\begin{tabular}{|c|c|c|}
\hline & HOT $(n=10)$ & HMV $(n=10)$ \\
\hline Age (years) & $68 \pm 9$ & $70 \pm 10$ \\
\hline BMI $\left(\mathrm{kgm}^{-2}\right)$ & $26 \pm 6$ & $21 \pm 3$ \\
\hline $\mathrm{FEV}_{1}(\mathrm{I}) /(\%)$ & $0.73 \pm 0.34 / 31 \pm 7$ & $0.56 \pm 0.16 / 22 \pm 12$ \\
\hline FVC (I)/(\%) & $1.79 \pm 0.56 / 65 \pm 12$ & $1.72 \pm 0.64 / 48 \pm 18$ \\
\hline $\mathrm{PaCO}_{2}(\mathrm{kPa})$ & $7.94 \pm 0.73$ & $8.22 \pm 0.71$ \\
\hline $\mathrm{PaO}_{2}(\mathrm{kPa})$ & $6.88 \pm 1.01$ & $6.54 \pm 0.81$ \\
\hline $\mathrm{HCO}_{3}(\mathrm{mmol} / \mathrm{l})$ & $35 \pm 3$ & $37 \pm 4$ \\
\hline MRC (/5) & $4 \pm 1$ & $5 \pm 1$ \\
\hline SGRO (/100) & $63 \pm 12$ & $66 \pm 14$ \\
\hline SRI-SS (/100) & $49 \pm 14$ & $52 \pm 16$ \\
\hline $\mathrm{O}_{2}$ prescription $(\mathrm{L} / \mathrm{min})$ & $1.2 \pm 0.7$ & $1.0 \pm 0.4$ \\
\hline
\end{tabular}

(HMV) and followed up at 6 weeks and 3 months. Patient assessment included anthropometrics, arterial blood gases and health related quality of life measures. Sleep disruption was assessed using actigraphy (Actiwatch spectrum, Philips-Respironics, Murrysville, Pennsylvania, USA) for 7 days following the assessment.

Results 36 patients have been recruited and randomised to date Abstract S119 table 1 show the baseline data for 20 patients that have completed follow-up to 3 months. Discharge ventilator settings were IPAP $26 \pm 3 \mathrm{cmH}_{2} \mathrm{O}$, EPAP $5 \pm 1 \mathrm{cmH}_{2} \mathrm{O}$ and back up rate $15 \pm 1 \mathrm{bpm}$ in the $\mathrm{HMV}$ group. Total sleep time during the first 2 weeks of HMV was significantly shorter than in those patients receiving HOT (?88 $\mathrm{min}$; 95\% CI 5 to $172 \mathrm{~min}, \mathrm{p}=0.04$ ). However, by 6 weeks there was no difference between the groups ( $\Delta 66 \mathrm{~min}$; $95 \% \mathrm{CI}-62$ to $194 \mathrm{~min}, \mathrm{p}=0.3)$. This was sustained at 3 months ( $\Delta 51 \mathrm{~min} ; 95 \% \mathrm{CI}-100$ to $202 \mathrm{~min}, \mathrm{p}=0.5$ ). There were no between group differences in wake after sleep onset, sleep efficiency or sleep latency at initial assessment or subsequent follow-up. Ventilator compliance at 6 weeks was $3 \mathrm{~h} 41 \mathrm{~min} \pm 1 \mathrm{~h} 41 \mathrm{~min}$ and at 3 months was $4 \mathrm{~h} 30 \mathrm{~min} \pm 1 \mathrm{~h} 44 \mathrm{~min}$.

Conclusion A reduction in total sleep time between patients receiving HMV compared with those receiving HOT was demonstrated during the initial period of acclimatisation to HMV. However, despite increasing ventilator usage during the follow-up period the difference in sleep duration between treatment groups reduced suggesting improved tolerability to NIV.

\section{S120 REFERENCE VALUES FOR THE INCREMENTAL SHUTTLE WALKING TEST IN A HEALTHY POPULATION}

doi:10.1136/thoraxjnl-2011-201054b.120

S L Harrison, N J Greening, L Houchen, J E A Williams, M Morgan, M Steiner, S J Singh. Pulmonary Rehabilitation Research Group, Glenfield Hospital, UHL NHS Trust, Leicester, UK

Introduction The assessment of functional exercise capacity is important in the evaluation of patients with chronic conditions and field walking tests are often used to assess functional exercise

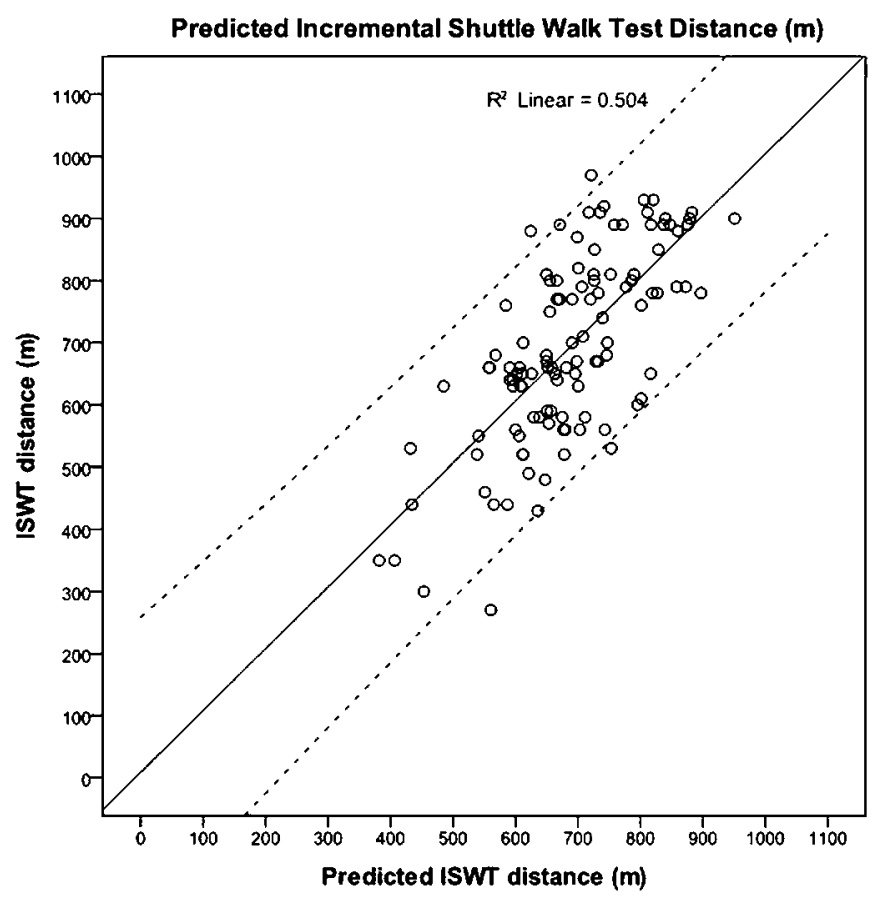

Abstract S120 Figure $1 \quad$ ISWTpred $=603.345+\left(61.870 \times \mathrm{FEV}_{1}\right)+$ $(6.960 \times 0 M V C)+(9.183 \times$ DUKE $)-(13.140 \times B M I)-(4.010 \times$ age $)$. 